\title{
Association of Physical Activity with Overweight and Obesity in Adolescent (10-14 Years) in Schools of Chandigarh, India
}

\author{
Arpit Arya ${ }^{1}$ and Saurabh Arya ${ }^{2 *}$ \\ ${ }^{1}$ Department of Foods and Nutrition, Government Home Science College \\ Chandigarh 160010, India \\ ${ }^{2}$ Department of Extension Education and Communication Management, CCS, \\ Haryana Agricultural University Hisar-125004, India \\ *Corresponding author
}

\begin{tabular}{|l|}
\hline Ke y w o r d s \\
Adolescent, \\
Overweight, \\
Physical activity \\
\hline Article Info \\
\hline Accepted: \\
12 September 2019 \\
Available Online: \\
10 October 2019
\end{tabular}

A B S T R A C T

The study was conducted with the objective to find the association of physical activity with that of overweight and obesity in school students of age group 10-14 years. The random sampling method was used for selecting the students of both the sexes from their respective classes $\left(5^{\text {th }}\right.$ to $9^{\text {th }}$ class) in both Government schools and Private schools of Chandigarh. It was observed that regular physical activity could assist in controlling overweight and obesity.

\section{Introduction}

Scientific cognizance about physical activity and well-being is of little importance if people cannot apprehend it and relate it to their lives. Obesity is a condition related with excess adipose tissue mass affecting children as well as adults, also defined as an upsurge BMI of more than 30. Incessant upsurge in overweight and obesity amongst children and adolescents is one of the utmost trepidations leading to life style conditions like atherosclerosis, dislipidemia, hyperinsulinemia, type 2 diabetes mellitus, hypertension, cardiovascular diseases, arthritis and most of behavioural glitches are few of the ramifications of obesity. From 1980 to 2013, prevalence of obesity in emerging economies has amplified in children and adolescents, from $8.1 \%$ to $12.9 \%$ for boys and from $8.4 \%$ to $13.4 \%$ in girls ( $\mathrm{Ng} \mathrm{M}$ et al., 2014). The exact cause of overweight and obesity in childhood is multifaceted, but regardless of the consideration of inherent and physiologic traits, a decrease in physical activity (PA), an increased amount of time devoted to sedentary regime and augmented calorie intake due to ecological variations seem to be an imperative aspects for weight gain (Drenowatz et al., 2014). A decrease in physical fitness (PF) has 
been concomitant with childhood obesity. It has been revealed that regular physical activity in children improves physical fitness, which helps in the controlling of childhood obesity (Gonazalez-suarez et al., 2013).

Thus the purpose of this study was to evaluate the association between weight status, Physical activity in students of 10-14 years old with special focus on gender and between days Physical activity alterations.

\section{Materials and Methods}

\section{Study design and sample size}

The study was designed in such a way that equal representation of students from different parts of Chandigarh could be made for the evaluation of physical activity for obesity.

Through random sampling method Students were chosen from Classes $5^{\text {th }}-9^{\text {th }}$ since adolescents of 10-14 years of age were expected to be studying in these classes from both Govt. and private schools. A total of 1030 subjects were interviewed for the study from government $(48.74 \%)$ and private schools $(51.26 \%)$ of Chandigarh.

\section{Data Collection}

A written consent was taken from Director of School Education after that oral permission was taken from Principal of schools and subjects that were surveyed. Age of each respondent was asked personally. For measuring degree of physical activeness modified PAQ-C scale was used (The Physical Activity Questionnaire).For studying the degree of physical activity various questions were asked from respondents based on types of sports/ games played over a week and how much they were active in doing that particular physical activity.

\section{Measurements}

BMI was calculated using Cut offs suggested by IAP growth chart committee were used to define overweight and obesity in this study as these growth charts are contemporary and also have good national representation in the manner that these are prepared from 14 Indian different cities from all 5 zones of IAP and thus give true picture of current growth sequence of children across the country (Khadilkar et al., 2015)

\section{Analysis of Data}

Statistical analysis was done using Prism software. Data was categorized into three groups: overweight (23 adult equivalent), obese (27 adult equivalent) non-overweight (< 23 adult equivalent) using age- and sexspecific BMI cut offs (Khadilkar et al., 2015). For statistical tests, $p<0.05$ was taken as the significant level.

\section{Results and Discussion}

Overall 1030 adolescents $(51.26 \%$ boys, $48.74 \%$ girls) in the age group of $10-14$ years of age were studied. Almost about $65 \%$ of students performing low to moderately active were found to be more obese and overweight than those who were highly physically active.

Figure 1 shows the degree of physical activity of boys and girls over a week. Low physically active implies that students were active only for 1-2 days over a week while moderately active denotes that students were active for about 3-4 days a week and highly active implies that students were active most days of the week. It was seen that only $23.68 \%$ boys and $17.46 \%$ girls indulged in low physical activity for 1-2 times a week. But a high percentage of boys (42.11\%) showed high physical activity for more than 5 times over a week and girls (46.58\%) showed interest in 
physical activity for more than 3 times over a week.

In a study carried out in Delhi (Singh et al., 2006) about two fifths (18.3\% of boys and $22.2 \%$ of girls) responded as not being physically active for 60 minutes per day at least three days in a week. Also, $54.4 \%$ of the boys and $69.3 \%$ of girls responded as not being involved in sports at school or at home. But in the current study maximum number of both boys and girls showed interest in school as well as in outside school activities.

Figure 2 illustrates the type of physical activity performed by the adolescents during recess time by both boys and girls. As mentioned earlier girls in the finding appeared to be less physically active than boys such that around $50 \%$ of them spent their recess in sitting and walking while almost $40 \%$ of boys were found to be involved in vigorous playing/ running during recess time. It was also seen that around $41 \%$ of boys and $31 \%$ of girls played vigorously during recess while rest of them either enjoys sitting ideally or prefer slow running during their recess time in school.

This figure 3 shows the preference and types of sports played by boys and girls on weekly basis. It was seen that girls shows less interest in sports/ games. Dance is the favourite activity performed by majority of girls (13\%) while boys enjoy bicycling, cricket and football that is boys took part in strenous activities more than girls do.

In a similar study also, boys were significantly more physically active than girls $(\mathrm{p}<0.05)$ and the level of physical activity was higher on weekdays than on weekend for both BMI groups ( $\mathrm{p}<0.05)$ (Arabatzi Fet et al., 2016).

Table 2 gives a brief view of degree of physical activity performed by both boys and girls as and when they get free time either in school hours or at home. It was found that majority of boys $(54.32 \%)$ spent their free time in sports/ games that involves high degree or dynamic physical activity inrelation with girls (16.63\%). Girls are found to be least energetic than boys in terms of displaying physical activity than boys as their major part of time in free hours was spent in talking, sitting and doing some sedentary work at home.

Though in another study (Gavarry et al., 2003) it was found that both Male and female subjects were more lethargic during free days than during school days at PS $(\mathrm{P}<0.05)$. No effect of the type of day and gender was witnessed for all indices of habitual physical activity at high schools.

As found earlier adolescents who were not involved in any physical activity for the past 7 days a week said the various reasons for not performing physical activity. Almost $60 \%$ of both boys and girls pointed out that their school homework was the main reason for them not performing any physical task. While $10.5 \%$ and $11.36 \%$ boys reported that they were injured while playing and were playing indoor games (games on computer, internet surfing etc) respectively. While girls stated that indoor playing (19\%) and being sick $(6.17 \%)$ was the main reason apart from doing schoolwork for not doing any physical activity.

In a study in accordance with current study it was found that body image and concerns over appearance may be barriers to physical activity; many girls note that getting 'sweaty' and messed-up hair and makeup limit their willingness to participate. Adolescents are also concerned with stereotypes (sporty females perceived as more masculine), bullying or teasing from their peers, and may lack sporting role models (Table 1-5). 
Table.1 Prevalence of overweight and obesity with respect to physical activeness of adolescents of 10-14 years of age

\begin{tabular}{|c|c|c|c|c|c|}
\hline Variable & Sub-variable & $\mathbf{n ~ \%}$ & $\begin{array}{c}\text { \%of non } \\
\text { overweight }\end{array}$ & $\begin{array}{c}\text { \% of } \\
\text { Overweight }\end{array}$ & $\begin{array}{c}\text { \%e of } \\
\text { Obese }\end{array}$ \\
\hline \multirow{2}{*}{ Adolescents } & Boys & 51.26 & 63.15 & 17.66 & 19.17 \\
\hline \multirow{2}{*}{ Physically active } & Girls & 48.74 & 71.08 & 19.87 & 9.03 \\
\cline { 2 - 6 } & Low & 47.76 & 61.38 & 19.72 & 18.9 \\
\cline { 2 - 6 } & moderate & 17.18 & 61.58 & 23.73 & 14.69 \\
\hline & high & 35.05 & 74.52 & 17.17 & 8.31 \\
\hline
\end{tabular}

Table.2 Free time of adoloscents spent in vigorous physical activity on weekly basis

\begin{tabular}{|c|c|c|}
\hline Frequency & Percentage of boys & Percentage of girls \\
\hline most of free time & 29.32 & 14.95 \\
\hline 1-2 time & 21.05 & 31.4 \\
\hline 3-4 times & 11.27 & 23.5 \\
\hline $\mathbf{5 - 6}$ times & 13.34 & 19.44 \\
\hline 7 or more times & 25 & 1.68 \\
\hline
\end{tabular}

Table.3 Reason given by adolescents for lack of physical activity

\begin{tabular}{|c|c|c|}
\hline Reason & $\begin{array}{c}\text { Percentage } \\
\text { of boys }\end{array}$ & $\begin{array}{c}\text { Percentage of } \\
\text { girls }\end{array}$ \\
\hline Injury & 10.5 & 2.8 \\
\hline Trip & 8.8 & 5.92 \\
\hline Indoor play & 11.36 & 19 \\
\hline Homework & 57.14 & 60.31 \\
\hline Household Chores & 5.3 & 5.8 \\
\hline Sick & 6.9 & 6.17 \\
\hline
\end{tabular}

Table.4 Association of physical activity with Overweight and Obesity

\begin{tabular}{|c|c|c|c|}
\hline \multirow{3}{*}{ Boys } & Physical Activity & $\begin{array}{c}\text { Percentage of } \\
\text { overweight }\end{array}$ & $\begin{array}{c}\text { Percentage of } \\
\text { Obesity }\end{array}$ \\
\hline \multirow{4}{*}{ Girls } & Low & 19.04 & 26.98 \\
\hline \multirow{3}{*}{} & Moderate & 10.98 & 12.08 \\
\cline { 2 - 4 } & High & 4.91 & 6.69 \\
\hline & Low & 21.83 & 18.39 \\
\hline & Moderate & 9.48 & 17.67 \\
\hline & High & 3.35 & 8.93 \\
\hline
\end{tabular}


Table.5 Association of overweight, obesity with physical activity

\begin{tabular}{|c|c|c|c|c|c|}
\hline \multicolumn{2}{|c|}{ Variable } & \multirow{2}{*}{$\begin{array}{l}N \\
211\end{array}$} & \multirow{2}{*}{$\begin{array}{c}\begin{array}{c}\text { Percentage of } \\
\text { Non-overweight }\end{array} \\
56.33\end{array}$} & \multirow{2}{*}{$\begin{array}{c}\text { Percentage of } \\
\text { Overweight and obese } \\
\text { ( } \geq 75 \text { th percentile) } \\
43.66\end{array}$} & \multirow{2}{*}{$\begin{array}{l}\text { P values } \\
<0.0001\end{array}$} \\
\hline \multirow{3}{*}{$\begin{array}{c}\text { Physically } \\
\text { active }\end{array}$} & Low & & & & \\
\hline & Moderate & 414 & 74.63 & 25.36 & \\
\hline & High & 405 & 88.08 & 11.91 & \\
\hline
\end{tabular}

Fig.1 Degree of physical activity of boys and girls

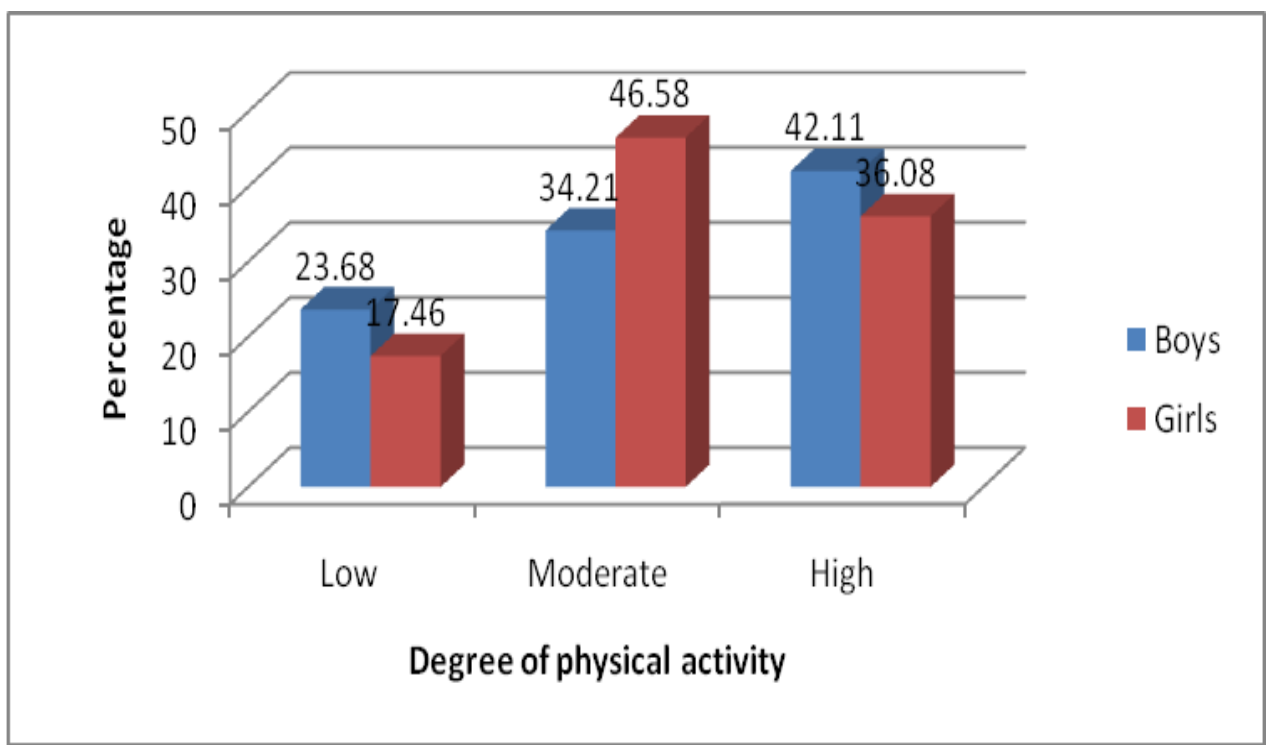

Fig.2 Type of activity performed by adolescents during recess time in school

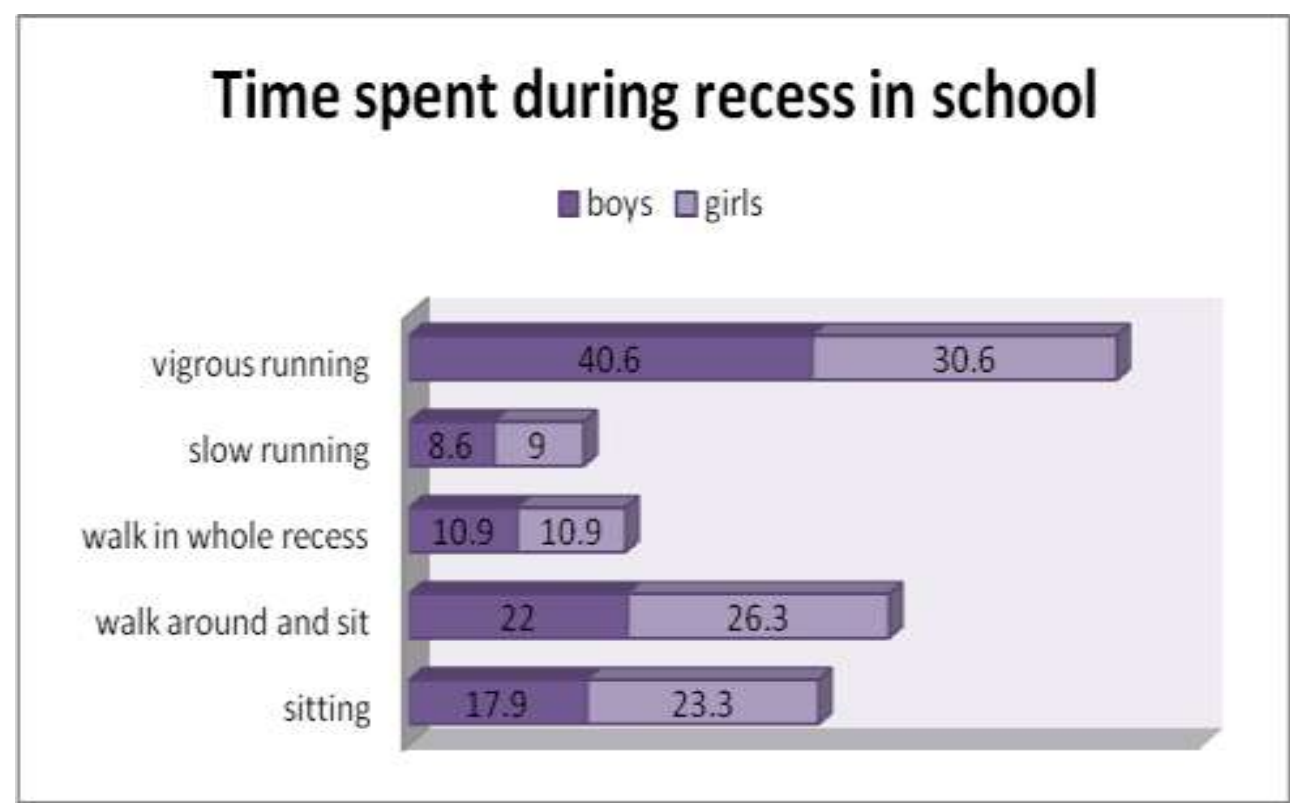


Fig.3 Sports most liked by boys and girls which are played during a week

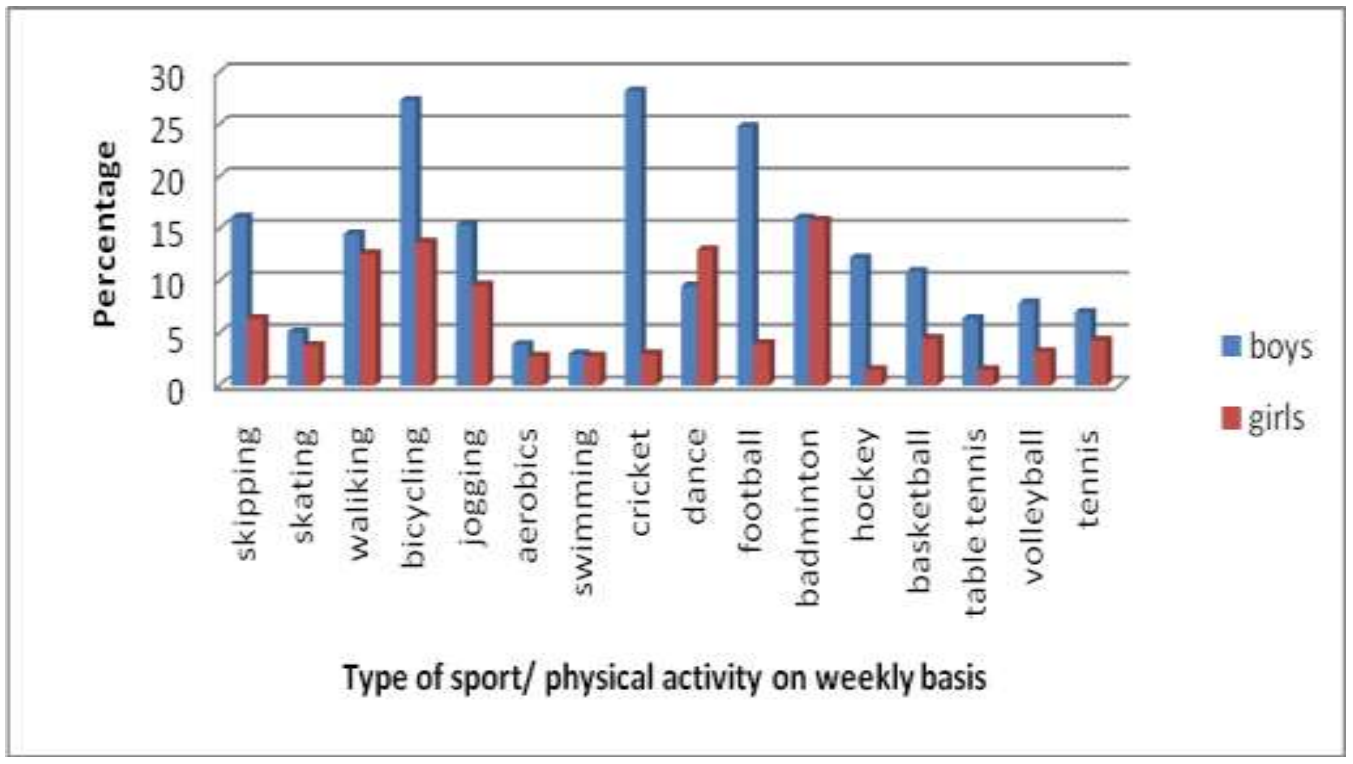

Fig.4 Association of physical activity of boys with overweight and obesity

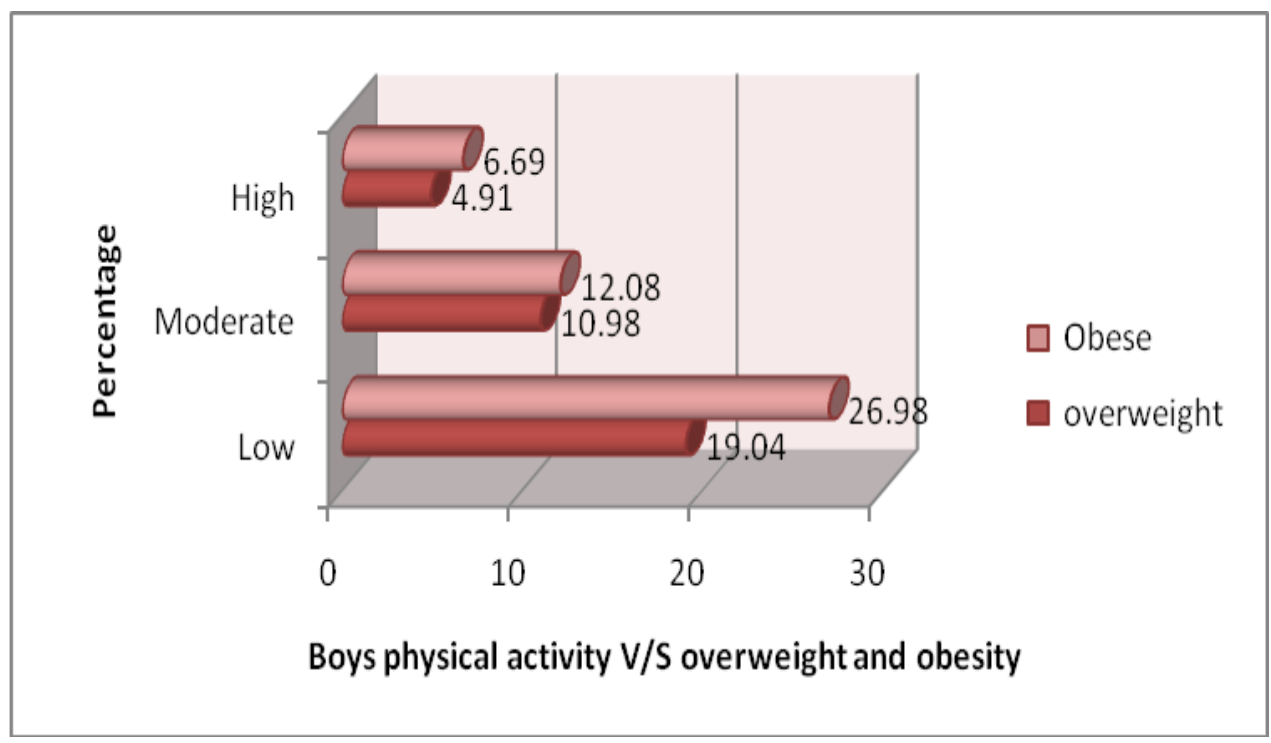

A lack of confidence in their own ability and skill level can also inhibit participation and enjoyment (O'Dea 2003, Women's sport and fitness foundation 2012).

Around $46 \%$ boys are found to be overweight and obese as they were found to be involved in low physical activity. This showed that degree of physically activity influences the prevalence of overweight and obesity. Boys (around 11\%) performing high physical activity are least overweight and obese as compared to those performing low activity. Around $40 \%$ of girls are found to be overweight and obese who did low physical activity (for 1-2 days a week) while the prevalence of being overweight and obese reduces to $12.28 \%$ girls performing high physical activity (more than 5 days a week). 
Unlike our study another study quoted that Physical activity was negatively associated with risk of obesity (odds ratio $[\mathrm{OR}]=0.93$; 95\% confidence interval [CI] [0.87, 0.98]). Though children who were obese and overweight were more possibly to have practical restrictions $(\mathrm{ORs}=1.58-1.61)$, their amusement towards physical activity involvement was not significantly dissimilar from that of the healthy-weight group (Hong et al., 2016).

Table 3 shows the association of obesity and overweight to that of degree of physical activity of boys and girls. The prevalence of obesity is more in both boys (19.04\%) and girls $(21.83 \%)$ who are least active (only for 1-2 days) over a week and while the percentage of overweight and obesity decreases as the level of physical activity increases in both boys and girls. However gender barely being the coefficient of obesity with the level of physical activity in adolescents. But more the physical activeness less are the chances to become overweight and obese. For example, a study compared moderate- and vigorous-intensity physical activity, the moderate level produced increased fitness, although often not to the same extent as the vigorous level.

In the present study, we observed a highly significant association ( $\mathrm{p}$ value $<0.0001$ ) between the incidence of overweight and obesity and the degree of physical activity. The difference is seen much more between the students doing physical activity for only 1-2 days a week to that of who are very much active during the whole week with the overweight and obesity.

The results are in accordance with another similar findings (Laxmaiah et al., 2007) where results clearly revealed that regular physical activity was found to be associated in reducing prevalence of overweight and obesity, the prevalence was significantly lower in the children who participated regularly in household chores, played outdoor games, performed exercise. The results clearly revealed that regular physical exercise is an important factor in the reduction of overweight/ obesity. The prevalence was significantly lower in children with high physical activity (Table 4 and 5).

The major conclusion drawn from the study is that low levels of physical activity are associated with a higher prevalence of overweight and obesity. The prevalence of overweight and obesity when compared with physical activity as a function of gender is minor because the overall prevalence remains almost same among adolescents. Consequently, the role of physical activity, games and sports should be stressed and amenities for outdoor games in schools relating to high physical activity should be elevated with obligatory hours of sports/ games.

\section{References}

Arabatzi F, Paschaleri Z, Papitsa A, Giagazoglou P, Kellis E (2016) Physical Activity, Physical Fitness and Overweight in Early Schoolchildren. J Sports Med Doping Stud 6:178. doi: 10.4172/2161-0673.1000178

Drenowatz C, Kobel S, Kettner S, Kesztyüs D, Steinacker JM (2014) Interaction of sedentary behaviour, sports participation and fitness with weight status in elementary school children. Eur J Sport Sci14:100-105.

Gavarry O, Giacomoni M, Bernard T, Seymat M, Falgairette G. (2003) Habitual physical activity in children and adolescents during school and free days. PubMed. 35(3):525-31.

Gonzalez-Suarez CB, Caralipio N, Gambito E, Reyes JJ, Espino RV, Macatangay R 
(2013) The association of physical fitness with body mass index and waist circumference in Filipino preadolescents. Asia Pac J Public Health. 25:74-83.

Hong I, Coker-Bolt P, R. Anderson K D., A. Velozo C. 2016. Relationship Between Physical Activity and Overweight and Obesity in Children: Findings From the 2012 National Health and Nutrition Examination Survey National Youth Fitness Survey. The American journal of Occupational Therapy, 70(5), 12-19

Khadilkar V, Yadav S, Aggarwal K, Tamboli $\mathrm{S}$, Banerjee M, Cherian A, P Goyal J, Khadilkar S, Kumaravel V, Mohan V, Narayanappa, Ray, Yewale V. Revised IAP Growth Charts for Height, Weight and Body Mass Index for 5- to 18year-old Indian Children. Indian Pediatrics 2015; 52: 47-55.

Laxmaiah A, Nagalla B, Vijayaraghavan K, Nair M. Factors affecting prevalence of overweight among 12-17 year old urban adolescents in Hyderabad, India. Obesity. 2007; 15:1384-1390

Ng M, Fleming T, Robinson M, Thomson B, Graetz N, et al., (2014) Global, regional, and national prevalence of overweight and obesity in children and adults during 1980-2013: a systematic analysis for the Global Burden of Disease Study 2013. Lancet 384: 766781.

O'Dea JA. Why do kids eat healthful food? Perceived benefits of and barriers to healthful eating and physical activity among children and adolescents. $J \mathrm{Am}$ Diet Assoc. 2003; 103: 497-501.

Singh AK, Maheshwari A, Sharma N, Anand K. Lifestyle Associated Risk Factors in Adolescents. Indian J Pediatr 2006; 73(10): 901-906.

The Physical Activity Questionnaire for Older Children (PAQ-C) and Adolescents (PAQ-A) Manual. College of Kinesiology, University of Saskatchewan, British Colombia.

\section{How to cite this article:}

Arpit Arya and Saurabh Arya. 2019. Association of Physical Activity with Overweight and Obesity in Adolescent (10-14 Years) in Schools of Chandigarh, India. Int.J.Curr.Microbiol.App.Sci. 8(10): 1533-1540. doi: https://doi.org/10.20546/ijcmas.2019.810.178 